\title{
Pengaruh Model Direct Intruction Berbantu Media Corong Berhitung Terhadap Hasil Belajar Matematika Materi Penjumlahan Bilangan
}

\author{
Indah Novarini ${ }^{*}$, Ahmad Nashir Tsalatsa ${ }^{2}$, Eka Sari Setianingsih ${ }^{3}$
}

1,2,3 Jurusan PGSD FIP Universitas PGRI Semarang, Indonesia.

\section{A R T I C L E I N F O}

Article history:

Received 20 August 2018

Received in revised form

9 September 2018

Accepted 15 October 2018

Available online 25

November 2018

Kata Kunci:

Model Direct Intruction

Hasil Belajar

Keywords:

Direct Intruction Model,

Learning Outcomes

\begin{abstract}
A B S T R A K
Penelitian ini bertujuan untuk mengetahui pengaruh dari model Direct Intruction berbantu media corong berhitung pada mata pelajaran matematika siswa kelas II. Jenis penelitian ini adalah penelitian kuantitatif dengan desain Pre Eksperimental Design dan jenis yang diambil adalah One-Group Pretest-Posttest Design. Sampel yang diambil adalah 18 siswa kelas II dengan menggunakan teknik Non Probability Sampling dengan sampling jenuh. Penelitian diperoleh ratarata nilai pretest sebesar 53,5 sedangkan rata-rata nilai posttest sebesar 76,5. Berdasarkan analisis data pada perhitungan uji $t$ diperoleh thitung $=12,2540$ dan ttabel $=1,740$. Karena thitung $>$ ttabel yaitu 12,2540>1,740 maka sesuai dengan rumusan hipotesis yang diujikan, $\mathrm{HO}$ ditolak dan Ha diterima. Bahwa model pembelajaran Direct Intruction berbantu media corong berhitung berpengaruh terhadap hasil belajar Matematika siswa kelas II SD Negeri Wanasari 02 Brebes.
\end{abstract}

\section{A B S T R A C T}

This study aims to determine the effect of the Direct Intruction-assisted media model of counting funnels on mathematics subjects of class II students. This type of research is a quantitative research with the Pre Experimental Design design and the type taken is One-Group Pretest-Posttest Design. The samples taken were 18 class II students using Non Probability Sampling technique with saturated sampling. The study obtained an average pretest score of 53.5 while the average posttest score was 76.5. Based on data analysis on the calculation of the $t$ test obtained $=12.2540$ and $=1.740$. Because $>$ is 12.2540> 1.740 then according to the formulation of the hypothesis tested, is rejected and is accepted. That the Direct Intruction learning model assisted with counting funnel media has an effect on the results of mathematics learning in the second grade students of Wanasari 02 Brebes Public Elementary School. 


\section{Pendahuluan}

Undang-Undnag Nomor 20 tahun 2003 menyatakan bahwa "Pendidikan adalah usaha sadar dan terencana untuk mewujudkan suasana belajar dan proses pembelajaran agar peserta didik secara aktif mengembangkan potensi dirinya untuk memiliki kekuatan spiritual keagamaan, pengendalian diri, kepribadian, kecerdasan, akhlak mulia, serta keterampilan yang diperlukan dirinya, masyarakat, bangsa dan Negara".

Merujuk dari pengertian tersebut pendidikan adalah usaha sadar dan terencana untuk mewujudkan suasana belajar yang nyaman, menyenangkan agar dapat menciptakan proses pembelajaran dengan efektif dan efisien. Dengan adanya pendidikan, setiap individu dapat mengembangkan potensi yang dimiliki sehingga dapat tercipta sumber daya manusia yang baik dan berkualitas untuk menunjang kemajuan bangsa.Mata pelajaran matematika wajib diberikan kepada semua siswa agar mereka memiliki pola pikir yang sistematis dan rasional seiring dengan peningkatan mutu pendidikan. Hal ini mengacu pada Peraturan Menteri Pendidikan Nasional Nomor 23 Tahun 2006 Pasal 1 tentang Standar Kompetensi Lulusan yang menjelaskan bahwa salah satu Standar Kompetensi Lulusan Satuan Pendidikan adalah menunjukkan kemampuan berfikir logis, sistematis, kritis, kreatif, dan inovatif dalam pengambilan keputusan serta mampu menganalisis serta memecahkan masalah.

Guru sebagai fasilitator bertugas memberikan bimbingan dan arahan kepada siswa agar memiliki kemampuan dalam pembelajaran khususnya pada mata pelajaran matematika. Namun, kondisi yang terjadi di sekolah, tidak sepenuhnya terjadi seperti yang diharapkan yaitu terjadinya proses pembelajaran yang terorganisir dengan baik. Sebaliknya yang terjadi adalah kurang optimalnya proses belajar mengajar yang terdapat di sekolah. Matematika memang tidak bisa lepas dari angka, membilang, menghitung dan sebagainya namun semuanya bermuara pada penyelesaian masalah. Pendekatan penyelesaian masalah dalam pembelajaran matematika harus dilakukan pendidik sejak dini untuk melatih kemampuan siswa dalam menyelesaikan masalah-masalah matematika. Berdasarkan haltersebut matematika memiliki peranan yang penting dalam pengetahuan,keterampilan dan kecerdasan. Dalam hal pengetahuan siswa harus bisa menguasaikonsep-konsep yang ada dalam pembelajaran matematika, dalam hal keterampilansiswa diharapkan mampu untuk mengaplikasikan konsep-konsep yang ada dalamkehidupan sehari-hari, dalam hal kecerdasan siswa mampu mengolah angkadengan baik dan menggunakan penalaran atau logika dengan benar. Konsepmatematika sering direpresentasikana dalam bentuk lambang-lambang atausimbol dan memiliki arti serta dapat digunakan dalam pemecahan masalah yangberkaitan dengan bilangan.

Dari hasil observasi diketahui bahwa 3 dari 18 siswa yang mampu memperoleh nilai diatas Kriteria Ketuntasan Minumum (KKM). Berdasarkan dari hal tersebut guru diharapkan mampu untuk mengatasi permasalahan maupun kendala yang dialami siswa dalam proses belajar. Dapat disimpulkan bahwa guru harus mampu untuk menciptakan suatu suasana pembelajaran yang aktif, kreatif, menarik serta bermakna bagi siswa agar siswa lebih optimal dalam menerima pelajaran serta informasi yang diberikan.

Model pembelajaran yang disolusikan untuk mengatasi masalah tersebut salah satunya adalah model pembelajaran Direct Intruction. Sintak Model Introction dapat dilihat pada Tabel 1.

Tabel 1. Sintak Model Direct Intruction

\begin{tabular}{|c|c|}
\hline Fase-fase & Perilaku Guru \\
\hline Fase 1: Establishing Set & Menjelaskan tujuan pembelajaran, \\
\hline $\begin{array}{l}\text { Menyampaikan tujuan dan } \\
\text { mempersiapkan siswa }\end{array}$ & $\begin{array}{l}\text { Informasi latar belakang pelajaran, } \\
\text { Mempersiapkan siswa untuk belajar. }\end{array}$ \\
\hline $\begin{array}{l}\text { Fase 2: Demonstrating } \\
\text { Mendemonstrasikan pengetahuan atau } \\
\text { keterampilan }\end{array}$ & $\begin{array}{l}\text { Mendemonstrasikan keterampilan yang benar, menyajikan } \\
\text { informasi tahap demi tahap. }\end{array}$ \\
\hline $\begin{array}{l}\text { Fase 3: Guided Practice } \\
\text { Membimbing pelatihan }\end{array}$ & Merencanakan dan memberi pelatihan awal. \\
\hline $\begin{array}{l}\text { Fase 4: Feed back } \\
\text { Mengecek pemahaman dan memberikan } \\
\text { umpan balik }\end{array}$ & $\begin{array}{l}\text { Mengecek apakah siswa telah berhasil melakukan tugas } \\
\text { dengan baik, memberikan umpan balik. }\end{array}$ \\
\hline $\begin{array}{l}\text { Fase 5: Extended Practice } \\
\text { Memberikan kesempatan untuk pelatihan } \\
\text { lanjutan dan penerapan }\end{array}$ & $\begin{array}{l}\text { Mempersiapkan kesempatan melakukan pelatihan lanjutan } \\
\text { dengan perhatian khusus pada penerapan situasi yang lebih } \\
\text { kompleks dalam kehidupan sehari-hari }\end{array}$ \\
\hline
\end{tabular}


Direct Intruction atau pembelajaran langsung menurut Anonim dalam (Rosdiani, 2012) adalah suatu model pengajaran yang menuntut guru sebagai model yang menarik bagi siswa dalam mendemonstrasikan pengetahuan atau keterampilan yang akan dilatihkan kepada siswa secara langkah demi langkah. Untuk menggunakan model pembelajaran langsung, guru harus memiliki keterampilan mengenai apa yang akan diajarkan kepada siswa seperti keterampilan, selain guru sebagai model dalam pembelajaran langsung dapat digunakan media visual. Menurut penelitian yang telah dilakukkan olehAuliyaRachmawati yaitu guru harus menguasai model Direct Instruction sebelum menerapkan model ini dalam pembelajaran. Guru juga dalam menerapkan model pembelajaran ini harus piawai dalam mengelola kelas dan mengetahui karakteristik siswa karena pada model ini guru sebagai pusatnya.

Model pembelajaran direct intruction dibantu menggunakan media corong berhitung dalam proses pembelajaran untuk mencapai tujuan pembelajaran yang diharapkan. Penggunaan media pembelajarn harus menjadi perhatian bagi guru, karena dengan penggunaan media proses pembelajaran akan lebih membantu untuk memperjelas materi yang disampaikan serta dapat memusatkan perhatian siswa. Tujuan pembelajaran berbantu media pembelajaran akan dapat hasil maksimal apabila pembelajaran berjalan secara efektif. Pembelajaran yang efektif adalah pembelajaran yang mampu melibatkan seluruh siswa secara aktif. (Sutanto, 2016).

Berdasarkan hal tersebut untuk belajar matematika butuh suatu media alternatif yang mampu untuk membuat konkret konsep matematika yang abstrak. Media pembelajaran yang dapat digunakan guru sangat beragam. Semua hal dapat dijadikan media pembelajaran seperti halnya mata pelajaran Matematika, pada materi operasi hitung guru dapat menggunakan corong berhitung untuk dijadikan suatu media pembelajaran. Dinamakan corong berhitung karena dalam peggunaannya menggunakan media corong untuk melakukan operasi hitung dimana corong sebagai tempat untuk memasukkan kelereng, kelereng sebagai bilangan yang akan dikenakan operasi hitung dan yang terakhir laci yaitu sebagai tempat hasil dari operasi hitung yang dilakukan.

Berdasarkan latar belakang tersebut maka akan dilakukan penelitian tentang "Pengaruh Model Direct Intruction Berbantu Media Corong Berhitung Terhadap Hasil Belajar Matematika Materi Penjumlahan Bilangan Pada Siswa Kelas II SD Negeri 02 Wanasari Kabupaten Brebes".

\section{Metode}

Penelitian ini adalah penelitian kuantitatif dengan desain Pre Eksperimental Design dan jenis yang diambil adalah One-Group Pretest-Posttest Design. Pretest digunakan untuk mengetahui kondisi awal pada siswa sebelum diberi perlakuan dan setelah itu diberi perlakuan, setelah diberi perlakuan siswa diberi posstest.

Teknik pengumpulan dara yang digunakan dalam penelitian ini yaitu berupa tes, dan observasi. Instrumen hasil belajar Matematika menggunakan tes berupa tes pilihan ganda. Untuk setiap soal yang benar diberi skor 1 dan untuk soal yang salah diberi skor 0 . Uji coba telah dilaksanakan pada tanggal 17 Juli 2018 dengan jumlah soal yang diujikan sebanyak 50 butir soal di kelas II SD Negeri Pebatan 03 dengan jumlah siswa 24.

Hasil dari ujicoba kemudian dianalisis baik uji validitas, reliabilitas, daya pembeda, dan tingkat kesukaran. Dari 50 soal diperoleh 30 soal yang valid dan 20 soal yang tidak valid. Hasil uji reliabilitas butir soal diperoleh koefosien reliabilitas sebesar 1,041 yang termasuk dalam kriteria reliabilitas tinggi. Hasil perhitungan daya pembeda diperoleh 44 butir soal tergolong jelek, 6 butir soal tergolongcukup.Untuk uji tingkat kesukaran setelah dilakukan perhitungan diperoleh 35 butir soal tergolong mudah dan 15 butir soal tergolong sedang. Dari hasil analisis uji validitas, reliabilitas, daya beda, dan tingkat kesukaran butir soal diperoleh 30 butir soal yang valid dengan reliabilitas yang tinggi dan memiliki daya pembeda dan taraf sukar yang baik sehingga 30 butir soal tersebut digunakan dalam penelitian untuk soal pretest dan posttest.

\section{Hasil dan Pembahasan}

Penelitian ini adalah penelitian kuantitatif dengan desain Pre Eksperimental Design dan jenis yang diambil adalah One-Group Pretest-Posttest Design. Data penelitian ini terdiri dari data awal yang diperoleh dari nilai pretest dan data akhir yang diperoleh dari nilai posttest.

Untuk menentukan instrumen penelitian maka diperlukan uji coba soal instrumen pada soal pretest dan posttest. Uji coba pada instrumen ini berjumlah 50 butir soal berbentuk pilihan ganda. Kemudian soal tersebut diujikan kepada siswa, setelah dilakukan uji coba soal instrumen kemudian hasil uji coba tersebut diuji dengan uji validitas, reliabilitas, taraf kesukaran, dan daya pembeda. Sehingga dapat diketahui soal yang valid. Pada awal pembelajaran kelas tersebut diberikan soal pretest berbentuk soal 
pilihan ganda untuk mengetahui seberapa besar tingkatan hasil belajar siswa pada mata pelajaran Matematika. Pada akhir pembelajaran, kelas tersebut diberikan posttest berupa soal yang sama dengan soal pretest. Berikut hasil data yang diperoleh pada penelitian di kelas dapat dilihat pada Tabel 1.

Tabel 2. NilaiPretest danPosttest

\begin{tabular}{ccc}
\hline Kategori & Pretest & Posttest \\
\hline Nilai terendah & 33 & 47 \\
Nilai tertinggi & 73 & 100 \\
Rata-rata & 53,5 & 76,5 \\
Jumlah siswa yang tidak tuntas & 12 & 5 \\
Jumlah siswa yang tuntas & 6 & 13 \\
Presentase ketuntasan & $33,3 \%$ & $72,2 \%$ \\
\hline
\end{tabular}

Pada tabel 2 terlihat bahwa pada saat pelaksanaanpretest terdapat rata-rata sebesar 53,5. Pada nilai tertinggi pretest yaitu 73, sedangkan nilai terendah yaitu 33. Pada pelaksanaan posttestterdapat peningkatan hasil belajar. saat pelaksanaan posttes sebesar 76,5. Kemudian untuk ketuntasan hasil belajar siswa, jumlah siwa yang tuntas belajar pada saat pretest berjumlah 6 siswa dan ketika posstest siswa yang tuntas berjumlah 13 siswa. Untuk mempermudah pemahaman hasil data di atas maka dapat dilihat pada diagram berikut:

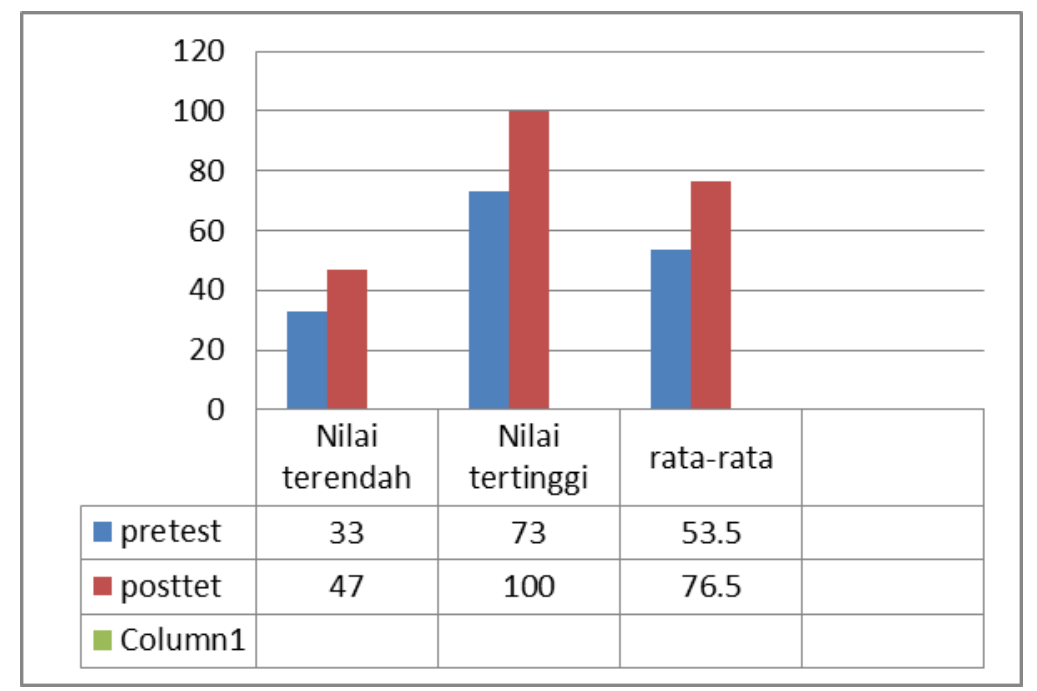

Diagram 1. Nilai, rata-rata pretest dan posttest

Setelah mendapatkan data hasil belajar akan dilakukan pengujian hipotesis.

Tabel 3. Hasil Uji Normalitas Awal

\begin{tabular}{ccccc}
\hline Kelas & $\mathrm{N}$ & $\mathrm{L}_{0}$ & $\mathrm{~L}_{\text {tabel }}$ & Kesimpulan \\
\hline Responden & 18 & 0,1799 & 0,200 & $\begin{array}{c}\text { Karena } \mathrm{L}_{0}<\mathrm{L}_{\text {tabel }} \text { yaitu } 0,1799<0,200 \text { maka }_{0} \\
\text { diterima, dan data berdistribusi normal. }\end{array}$ \\
\hline Kelas & $\mathrm{N}$ & $\mathrm{L}_{0}$ & $\mathrm{~L}_{\text {tabel }}$ & Kesimpulan \\
\hline Responden & 18 & 0,1231 & 0,200 & $\begin{array}{c}\text { Karena } \mathrm{L}_{0}<\mathrm{L}_{\text {tabel }} \text { yaitu } 0,1231<0,200 \text { maka } \mathrm{H}_{0} \\
\text { diterima, dan data berdistribusi normal. }\end{array}$ \\
\hline
\end{tabular}

Pada analisis data uji normalitas akhir diperoleh $=0,1231$ yang lebih kecil dari $=0,200$.Nilai kritis uji liliefors dengan taraf signifikan $a=5 \%$ dan $n=18$ diperoleh $=0,200$. Sehingga dapat disimpulkan bahwa yaitu: 0,1231<0,200 maka $\mathrm{H}_{0}$ diterima. 
Tabel 5. Hasil Uji t

\begin{tabular}{cccccccc}
\hline Subjek & Hasil belajar & Rata-rata & $\mathrm{N}$ & $\mathrm{Md}$ & $\Sigma X^{2} \mathrm{~d}$ & $t_{\text {hitung }}$ & $t_{\text {tabel }}$ \\
\hline Siswakelas II & Pretest & 53,5 & \multirow{2}{*}{18} & 23 & 1078 & 12,2540 & 1,740 \\
$\begin{array}{c}\text { SDN Wanasari } \\
\text { 02 Brebes }\end{array}$ & Posttest & 76,5 & & & & & \\
\hline
\end{tabular}

Pada analisis uji $\mathrm{t}$ dari perhitungan di atas dengan $\mathrm{db}=\mathrm{N}-1=18-1=17$ diperoleh $=12,2540$. Selanjutnya dikonsultasikan dengan tabel taraf signifikan 5\% dengan $=1,740$, maka. Dengan demikian koefisien sebesar 12,2540 adalah signifikan pada taraf 5\%. Atas dasar perhitungan tersebut maka dapat dikatakan bahwa ada pengaruh model Direct Intruction berbantu Media Corong Berhitung terhadap hasil belajar Matematika pada siswa kelas II SDN Wanasari 02 Brebes Tahun Ajaran 2018/2019.

Model pembelajaran direct intruction atau pembelajaran langsung menurut Anonim dalam (Rosdiani, 2012) adalah suatu model pengajaran yang menuntut guru sebagai model yang menarik bagi siswa dalam mendemonstrasikan pengetahuan atau keterampilan yang akan dilatihkan kepada siswa secara langkah demi langkah. Untuk menggunakan model pembelajaran langsung, guru harus memiliki keterampilan mengenai apa yang akan diajarkan kepada siswa seperti keterampilan, selain guru sebagai model dalam pembelajaran langsung dapat digunakan media visual. Menurut penelitian yang telah dilakukkan oleh Auliya Rachmawati yaitu guru harus menguasai model Direct Instruction sebelum menerapkan model ini dalam pembelajaran. Guru juga dalam menerapkan model pembelajaran ini harus piawai dalam mengelola kelas dan mengetahui karakteristik siswa karena pada model ini guru sebagai pusatnya.

Secara deskriptif pada saat pelaksanaan pretest terdapat rata-rata sebesar 53,5. Pada nilai tertinggi pretest yaitu 73, sedangkan nilai terendah yaitu 33. Pada pelaksanaan posttestterdapat peningkatan hasil belajar. saat pelaksanaan posttes sebesar 76,5. Kemudian untuk ketuntasan hasil belajar siswa, jumlah siwa yang tuntas belajar pada saat pretest berjumlah 6 siswa dan ketika posstest siswa yang tuntas berjumlah 13 siswa. Uji normalitas akhir diperoleh $=0,1231$ yang lebih kecil dari $=0,200$. Nilai kritis uji liliefors dengan taraf signifikan $a=5 \%$ dan $n=18$ diperoleh $=0,200$. Sehingga dapat disimpulkan bahwa yaitu: 0,1231<0,200 maka H0 diterima. Dan uji t dari perhitungan di atas dengan db $=\mathrm{N}-1=18-1=17$ diperoleh $=12,2540$. Selanjutnya dikonsultasikan dengan tabel taraf signifikan $5 \%$ dengan $=1,740$, maka. Dengan demikian koefisien sebesar 12,2540 adalah signifikan pada taraf $5 \%$. Atas dasar perhitungan tersebut maka dapat dikatakan bahwa ada pengaruh model Direct Intruction berbantu Media Corong Berhitung terhadap hasil belajar Matematika pada siswa kelas II SDN Wanasari 02 Brebes Tahun Ajaran 2018/2019.

Temuan penelitian yang menunjukkan bahwa model Direct Intruction berbantu Media Corong Berhitung berpengaruh terhadap hasil belajar Matematika siswa yaitu penelitian yang dilakukan oleh Susiana (2015) dengan judul Pengaruh Model Direct Instruction Berbantuan Multimedia Terhadap Motivasi Belajar Dan Pencapaian Kompetensi Pembuatan Desain Busana yang memperoleh hasil terdapat perbedaan pengaruh yang signifikan penggunaan model pengajaran langsung (direct instruction) berbantuan multimedia terhadap pencapaian kompetensi pembuatan desain busana antara kelas eksperimen dan kelas kontrol. Penelitian yang sama juga dilakukan oleh Meyta Pritandhari (2017) dengan judul Implementasi Model Pembelajaran Direct Instruction Untuk Meningkatkan Kemampuan Berpikir Kreatif Mahasiswa yang memperoleh hasil bahwa metode direct instruction dapat diaplikasikan untuk berbagai mata kuliah yang bertujuan untuk melatih mahasiswa dalam kegiatan pembelajaran. Alia dan Supriyono (2013) mengkombinasikan model Direct Instruction dengan Keterampilan Proses Sains dalam pembelajaran konsep fisika, pada penelitian ini guru mampu mengelola pembelajaran dengan baik, siswa mengalami peningkatan hasil belajar secara signifikan dan respon siswa terhadap model Direct Instruction dengan menggunakan Keterampilan prose siswa juga baik. Peneliti lainnya Safitri dkk (2013) mengatakan bahwa terdapat pengaruh yang signifikan pendekatan Multiple Intellegences melalui model pembelajaran langsung (Direct Instruction) terhadap sikap dan hasil belajar Kimia peserta didik kelas XI IPA SMA Negeri I Tellu Limpoe.

\section{Simpulan dan Saran}

Berdasarkan hasil penelitian dan pembahasan dalam penelitian ini dapat disimpulkan bahwa model Direct Intruction berbantu media corong berhitung berpengaruh terhadap hasil belajar matematika materi penjumlahan bilangan siswa kelas II SD Negeri Wanasari 02 Kabupaten Brebes. Hal ini dibuktikan dengan analisis uji t dimana $=12,2540>=1,740$ dengan rata-rata nilai pada kelas adalah 76,5 dan presentase ketuntasan hasil belajar mencapai $72,2 \%$ dengan 13 siswa yang mencapai ketuntasan hasil 
belajar dari 18 siswa. Sedangkan sebelum diberikan model Direct Intruction berbantu media corong berhitung, presentase siswa yang mencapai ketuntasan hasil belajar hanya 33,3\% yaitu 6 dari 18 siswa yang telah mencapai ketuntasan hasil belajar dengan rata-rata nilai 53,5.

\section{Daftar Rujukan}

Alia, N dan Supriyono, 2013. Penerapan Model Direct Instruction dengan Menggunakan Keterampilan Proses Sains Untuk Meningkatkan Hasil Belajar Siswa Kelas X SMA Negeri 1 Bangkalan Pada Materi Pokok Azas Black. Jurnal Inovasi Pendidikan Fisika, Vol.02, No.03

Arikunto, Suharsimi. 2010. Prosedur Penelitian Suatu Pendekatan Praktik. Jakarta: Rineka Cipta.

Arsyad, Azhar. 2013. Media Pembelajaran. Jakarta: PT Raja Grafindo Persada.

BSNP.2006. Standar Isi Sekolah Dasar/Madrasah Ibtidaiyah.Jakarta: Balitbang.

Djamarah, Syaiful Bahri. 2011. Psikologi Belajar. Jakarta: PT Rineka Cipta.

Griffin,P., Gillis, S. \& Calvitto, L. (2007). Standards-referenced assessment for vocational education and training in schools. Australian Journal of education. Vol. 51 No. 1, 2007, 19 -38 Assessment Research Centre The University of Melbourne

Hamdani. 2011. Strategi Belajar Mengajar. Bandung : CV Pustaka Setia.

Heruman. 2014. Model Pembelajaran Matematika Di Sekolah Dasar. Bandung: PT Remaja Rosdakarya

Khoeriyah, Ni'matul. 2016. Pengaruh Model Direct Instruction Terhadap HasilBelajar SBK Materi Membuat Karya Kolase Siswa Kelas IV SDN GugusKenanga Kabupaten Kebumen. Skripsi. Jurusan Pendidikan Guru SekolahDasar. Fakultas Ilmu Pendidikan. Universitas Negeri Semarang.

Mariati, Desak Putu dkk. 2014. Penerapan Model Pembelajaran Langsung (Direct Instruction) Berbantuan Media Seni Melipat Kertas Untuk Meningkatkan Kemampuan Motorik Halus Anak Tk Shanti Kumara Iii Sempidi. Jurusan Pendidikan Guru Pendidikan Anak Usia Dini, Volume 2, No 1.

Pritandhari, Meyta. 2017. Implementasi Model Pembelajaran Direct Instruction Untuk Meningkatkan Kemampuan Berpikir Kreatif Mahasiswa. Jurnal Pendidikan Ekonomi UM Metro, Vol.5, No.1.

Rachmawati, Auliya. 2015. Keefektifan Model Direct Instruction terhadap Aktivitas dan Hasil Belajar Siswa pada Materi Bermain Alat Musik Melodi di Kelas IV SDN Kepandean 03 Kabupaten Tegal

Rosdiani, Dini. 2012. Model Pembelajaran Langsung dalam Pendidikan Jasmani dan Kesehatan. Bandung: Alfabeta.

Sakti. I, Puspasari. Y.M. dan Risdianto. E, 2012, Pengaruh Model Pembelajaran Langsung (Direct Instruction) Melalui Media Animasi Berbasis Macromedia Flash Terhadap Minat Belajar dan Pemahaman Konsep Fisiska Siswa di SMA Plus Negeri 7 Kota Bengkulu, Jurnal Exacta, vol. X No. 1.

Safitri, Bancong. H dan Husain. H, 2013. Pengaruh Pendekatan Multiple Intelegences Melalui Model Pembelajaran langsung Terhadap Sikap dan Hasil Belajar Kimia Peserta Didik di SMA Negeri 1 Tellu Limpoe. Jurnal pendidikan IPA Indonesia vol (2), no (2)

Setiawan. W, Fitrajaya. E dan Mardiyanti.T, 2010, Penerapan Model Pengajaran Langsung (Direct Instruction) Untuk Meningkatkan Pemahaman Belajar Siswa dalam Pembelajaran Rekayasa Perangkat Lunak (RPL), Jurnal Pendidikan Teknologi Informasi dan Komunikasi (PITK), Vol. 3, No. 1.

Sori, Elpian. 2014. Penerapan Model Pembelajaran Langsung Dengan Media Video Untuk Meningkatkan Kemampuan Lempar Turbo Siswa Kelas IV SD.Negeri 06 Lebong Atas Kabupaten Lebong.http://repository.unib.ac.id/9037.pdf. Diakses 21 Juni 2018. 
Sudjana. (2005). Metode Statistika. Bandung: PT Tarsito.

Sugiyono. (2016). Metode Penelitian Kuantitatif, Kualitatif, dan R\&D. Bandung: Alfabeta.

Susiana, Ratih. 2015. Pengaruh Model Direct Instruction Berbantuan Multimedia Terhadap Motivasi Belajar Dan Pencapaian Kompetensi Pembuatan Desain Busana. Jurnal Pendidikan Vokasi, Vol 5, Nomor 3. 